\title{
Determination of the energy expenditure of penned and grazing sheep from estimates of carbon dioxide entry rate
}

\author{
BY J. L. CORBETT \\ CSIRO, Division of Animal Physiology, Pastoral Research Laboratory, Armidale, \\ NSW, 2350, Australia \\ AND D. J. FARRELL, R. A. LENG AND G. L. McCLYMONT \\ Department of Biochemistry and Nutrition, \\ University of New England, Armidale, NSW, 235 I, Australia \\ AND B. A. YOUNG* \\ Department of Physiology, \\ University of New England, Armidale, NSW, 235 I, Australia \\ (Received 27 October 1970-Accepted 15 March 1971)
}

\begin{abstract}
I. $\mathrm{NaH}^{14} \mathrm{CO}_{3}$ was infused at a constant rate either subcutaneously or intraperitoneally into sheep kept in a uniform environment and consuming a standard amount of food each hour. After $3 \mathrm{~h}$ of infusion the specific radioactivity (SR) of $\mathrm{CO}_{2}$ obtained by acidification of samples of blood taken from the right atrium showed no significant change with time until after $22 \mathrm{~h}$ when the infusions were stopped.

2. Entry rates of $\mathrm{CO}_{2}(1 / \mathrm{h})$ in sheep were estimated from the ratio of rate of infusion of ${ }^{14} \mathrm{CO}_{2}$ as $\mathrm{NaH}^{14} \mathrm{CO}_{8}(\mu \mathrm{Ci} / \mathrm{h})$ to the $\mathrm{SR}$ of $\mathrm{CO}_{2}(\mu \mathrm{Ci} / \mathrm{l})$ in samples of jugular venous blood, urine and exhaled gas taken after infusions had been in progress for at least $3 \mathrm{~h}$. Concurrently, rates of energy expenditure were calculated from the gaseous exchanges over periods of $60-90 \mathrm{~min}$ which were determined for grazing sheep by use of re-entrant tracheal cannulation and metering and analysis of exhaled gas, or for housed sheep by measurement in respiration chambers.

3. Significant positive relationships were found between entry rate, the independent variable, and the contemporary energy expenditure. Equations obtained for grazing sheep were not significantly different from those obtained for other, housed, sheep when both groups were infused subcutaneously and $\mathrm{CO}_{2}$ for assay of radioactivity was obtained in all instances from blood, or in all instances from urine.

4. With subcutaneous infusion the equation relating energy expenditure to entry rate estimated from the SR of urinary $\mathrm{CO}_{2}$ differed significantly from that where entry rate was derived from radioactivity assays of blood or exhaled $\mathrm{CO}_{2}$. There was also a significant difference between two equations where entry rates were determined from the SR of blood $\mathrm{CO}_{2}$ but route of infusion was in the one instance intravenous and in the other was subcutaneous. Reasons for the differences between equations are discussed.

5. Changes in the rates of energy expenditure of sheep effected by intermittent exercise on a treadmill were reflected in changes in $\mathrm{CO}_{2}$ entry rates. Values for the energy cost of horizontal locomotion by the sheep were derived from the entry rates and were similar in magnitude to those reported by other workers.

6. It is suggested that the method of determining energy expenditure from $\mathrm{CO}_{2}$ entry rate may be adapted for use on many species of animal in a variety of environments.
\end{abstract}

The usual methods of animal calorimetry require close restraint of the subjects. Portable equipment for determining the energy expenditure of humans from respiratory gaseous exchanges has been adapted for use on domestic livestock, but the use of a face mask prevents feeding and may restrict other activities. An alternative is

* Present address: Department of Animal Science, University of Alberta, Edmonton, Canada. 
fistulation of the trachea, which has been used in studies on grazing cattle (Flatt, Waldo, Sykes, \& Moore, 1958) and sheep (Corbett, Leng \& Young, 1969), but this technique is not widely applicable.

Attempts have been made to establish indices of energy expenditure that can be used when measurements of respiratory gaseous exchanges are impracticable. Webster (1967) and Brockway \& McEwan (1969) measured the heart rate of sheep; the relationship with energy expenditure varied between animals, and though all nine in the two studies were long accustomed to handling and experimental routine, energy expenditure could be predicted to within $\pm 10 \%$ for only three sheep, to within \pm 20 to $25 \%$ for two and not at all for four. Lifson, Gordon \& McClintock (1955) and Lifson \& McClintock (I 666 ) developed a method for estimating gaseous exchanges, and thence energy expenditures from the difference between the apparent turnover rates of the hydrogen and oxygen of body water when labelled with $\mathrm{D}_{2}{ }^{18} \mathrm{O}$. The method has been used on mice, rats and pigeons but the amount of $\mathrm{D}_{2}{ }^{18} \mathrm{O}$ required for a larger animal, such as the sheep, would be very costly.

Changes in the specific radioactivity (SR) of carbon dioxide in animal tissues and in expired gas after administration of a variety of ${ }^{14} \mathrm{C}$-labelled materials have been used to assess the contributions of individual substrates to total oxidative metabolism. In the work now reported the apparent rates of entry of $\mathrm{CO}_{2}$ into the body pools of $\mathrm{CO}_{2}$ in sheep, indoors and at pasture, were examined as a possible index of $\mathrm{CO}_{2}$ production, and thence of energy expenditure, by the animal as a whole. The immediate objective was to establish empirical relationships that would allow prediction of the energy expenditure of freely grazing sheep. For this reason, procedures used were generally those that might be most appropriate in the field.

Practical problems would arise if a single injection of $\mathrm{NaH}^{14} \mathrm{CO}_{3}$ was used to determine $\mathrm{CO}_{2}$ entry rate in an unrestrained animal free to engage in a variety of activities and not held to a uniform dietary regimen. It is unlikely that there would be a steady rate of $\mathrm{CO}_{2}$ production within the body during the period of measurement, and it would be difficult to obtain samples sufficient in number to permit adequate description of the rate of decline in SR and thence satisfactory estimation of entry rate over that period. Frequent disturbance of the animals for sampling could introduce artifacts in the results.

With continuous infusion, frequent sampling at precisely determined times is not required. Entry rate $\left(\mathrm{CO}_{2}, 1 / \mathrm{h}\right)$ at any particular time may be calculated from the expression:

$$
\frac{\text { rate of infusion of }{ }^{14} \mathrm{CO}_{2}(\mu \mathrm{Ci} / \mathrm{h})}{\text { SR of a } \mathrm{CO}_{2} \text { sample }(\mu \mathrm{Ci} / 1)},
$$

provided a constant rate of infusion has been maintained for a sufficient time before observations are made for equilibration of the ${ }^{14} \mathrm{CO}_{2}$ with the total body pool of $\mathrm{CO}_{2}$. The time from the start of an infusion required for equilibrium, as indicated by approach to constant $\mathrm{SR}$ of $\mathrm{CO}_{2}$ in sheep held in uniform conditions, was examined before studies were made of relationships between $\mathrm{CO}_{2}$ entry rate and energy expenditure. When the animal is in steady state a few samples of body $\mathrm{CO}_{2}$ should yield a 
satisfactory estimate of entry rate. When there is variation about a daily mean entry rate, an estimate of the mean rate could be obtained from a sample obtained by continuous collection or from a number of samples taken at appropriate intervals. In the latter instance the frequency of sampling required will be determined by how rapidly changes in entry rate occur and this was examined in one of the experiments reported here.

Apart from one experiment where samples of exhaled gas were obtained from tracheostomized grazing sheep, $\mathrm{CO}_{2}$ for radioactivity assay was obtained from the animals by acidification of samples of venous blood and sometimes of urine. The term $\mathrm{CO}_{2}$ in this paper thus refers to all acid-volatile carbon dioxide in the animals' body, whether present as $\mathrm{CO}_{2}, \mathrm{HCO}_{3}^{-}, \mathrm{CO}_{3}^{2-}, \mathrm{H}_{2} \mathrm{CO}_{3}$, or carbamino- $\mathrm{CO}_{2}$. Entry rates are expressed in terms of $1 \mathrm{CO}_{2} / \mathrm{h}$ for immediate comparison with energy expenditures determined from gaseous exchanges over periods of from 60 to $90 \mathrm{~min}$. Should entry rate in terms of $\mathrm{mg} \mathrm{CO}$ carbon/min be preferred, this may be calculated by multiplying the $1 \mathrm{CO}_{2} / \mathrm{h}$ values by $8 \cdot 99$.

The $\mathrm{CO}_{2}$ entry rate technique for estimating energy expenditure has been outlined by Young, Leng, White, McClymont \& Corbett (1969).

\section{EXPERIMENTAL}

Adult Merino sheep accustomed to the various procedures were used in all experiments. The live weights reported exclude the weight of the fleeces, estimated from the length using relationships between length and fleece weight determined at shearing.

\section{Materials and analyses}

Infusate. $\mathrm{NaH}^{14} \mathrm{CO}_{3}$ was obtained from the Radiochemical Centre, Amersham, $\mathrm{UK}$ and was diluted with sterile saline $(0.9 \%, \mathrm{w} / \mathrm{v}, \mathrm{NaCl})$ containing I $\mathrm{mg} \mathrm{NaHCO}_{3} /$ $\mathrm{ml}$ as carrier. Rates of infusion were in the ranges $\mathrm{I}-4 \mu \mathrm{Ci} / \mathrm{h}$ in $3-6 \mathrm{ml}$.

Infusion pumps. Palmer infusion pumps (C. F. Palmer Co., London) were used in Expt I. Pumps powered by batteries ( $10 \mathrm{~V}, 25^{\circ} \mathrm{g}$ ) were used in all other experiments. These pumps are readily carried by sheep (Leng, Corbett \& Brett, 1968) and the coefficient of variation of the mean volume of infusate delivered per hour was about I \%.

Radioactivity assay of $\mathrm{CO}_{2}$. The $\mathrm{CO}_{2}$ was extracted from exhaled gas (Expt 3) by bubbling it through $\mathrm{CO}_{2}$-free $\mathrm{N}-\mathrm{NaOH}$. Other procedures were, with minor modi-

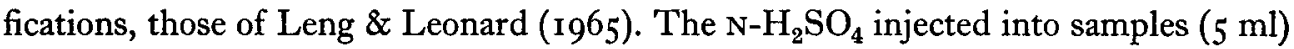
of blood and urine contained $\mathrm{I} \%(\mathrm{w} / \mathrm{v}) \mathrm{CuSO}_{4}$ to prevent bacterial action. Without this addition abnormally large amounts of $\mathrm{CO}_{2}$ of low SR were sometimes obtained if absorption into $\mathrm{NaOH}$ was allowed to continue for $24 \mathrm{~h}$ or more. Precipitates of $\mathrm{BaCO}_{3}$ were reduced to fine powder by rapid vibration (Whirlimixer; Scientific Industries (UK) Ltd, London) in tared scintillation vials with glass beads which were removed before determination of dry weight and subsequent counting. The small particle size minimized self absorption of radioactivity even with quantities of $\mathrm{BaCO}_{3}$ two or three times larger than the $20-40 \mathrm{mg}$ usually assayed. 


\section{Expt I}

Four wethers, $39-43 \mathrm{~kg}$ in weight, were held in individual metabolism crates in a room with continuous artificial light and at an ambient temperature of $20 \pm 2^{\circ}$. Each sheep was given and consumed $33 \mathrm{~g}$ good-quality lucerne chaff each hour $(800 \mathrm{~g} / \mathrm{d})$, and had access to water at all times.

Several hours before infusions were started a catheter was inserted into the right atrium of each sheep via a jugular vein and filled with physiological saline containing 50 i.u. heparin $/ \mathrm{ml}$. In addition, a catheter for infusion was inserted with the aid of a guide wire, and under local anaesthesia (Xylocaine), $15 \mathrm{~cm}$ through the right flank of two sheep into the peritoneal cavity, and a similar distance subcutaneously into the other two sheep in the left mid-lumbar region close to the spinous processes. To minimize the possibility of leakage of infusate around the outside of the subcutaneous catheters, a suture passing through subcutaneous tissue was tied around the catheter about $\mathrm{I} \mathrm{cm}$ beyond the point of entry.

Infusions of $\mathrm{NaH}^{14} \mathrm{CO}_{3}$ were continued for $22 \mathrm{~h}$, and blood was taken from the right atrium at approximately $60 \mathrm{~min}$ intervals beginning $\mathrm{I} h$ (sheep $\mathrm{B}, \mathrm{D}$ ) or $\mathrm{I2} \mathrm{h}$ (sheep A, C) after infusion started. Further samples of blood were taken for about $24 \mathrm{~h}$ after infusion stopped.

\section{Expt 2}

Two ewes of about $40 \mathrm{~kg}$ live weight were held in closed-circuit respiration chambers (Graham, 1962) and given lucerne chaff $a d$ lib.; food but not water was then withdrawn for $2 \mathrm{~d}$. Catheters were inserted into an external jugular vein and the bladder of each ewe, and $\mathrm{NaH}^{14} \mathrm{CO}_{3}$ was infused subcutaneously, as in Expt I, while the sheep were fed and while they were fasted.

Gaseous exchanges of the two sheep were measured in thirteen periods each of $\mathrm{I} \mathrm{h}$ while they were given food and during the $2 \mathrm{~d}$ of fast; the first periods started about $4 \mathrm{~h}$ after the start of infusion. During the $\mathrm{I} h$ periods, chamber gas was pumped continuously through a silica gel absorption train to maintain approximately constant humidity. Exchanges were calculated from the known volumes of the chambers and associated gas circuits, and the observed decrease in $\mathrm{O}_{2}$ and increase in $\mathrm{CO}_{2}$ concentrations.

Energy expenditure $(Y, \mathrm{kcal})$ was calculated by the method of Brouwer (1965), except that no allowance was made for urinary excretions or for methane:

$$
Y=\left(1 \mathrm{O}_{2} \times 3 \cdot 87\right)+\left(1 \mathrm{CO}_{2} \times 1 \cdot 20\right) \text {. }
$$

At the end of each period, immediately the chamber door was opened, a sample of jugular venous blood was withdrawn, and at the end of ten of the thirteen periods, a sample of urine was taken by draining the bladder through the catheter, which had been kept sealed during the preceding $\mathrm{I} h$.

\section{Expt 3}

Studies were made on ten sheep, two ewes and eight wethers, grazing a variety of types of pasture of $0 \cdot 3-1 \cdot 0$ ha in area. For several months the amounts of herbage available had been controlled by varying stocking intensity, as described by Young 
\& Corbett (1968), so that body condition varied widely and the range in live weight was $2 \mathrm{I}-45 \mathrm{~kg}$.

Two fistulas had been established in the trachea of each sheep (Young \& Webster, 1963), permitting re-entrant cannulation and metering and sampling of exhaled gas by means of a Max Planck meter as described by Corbett et al. (1969). The exhaled gases included gases eructated from the rumen. Energy expenditure over forty-two periods, each of approximately $\mathrm{I} h$, was calculated from oxygen consumption and $\mathrm{CO}_{2}$ production as in Expt 2.

All infusions of $\mathrm{NaH}^{14} \mathrm{CO}_{3}$ were made subcutaneously and had been in progress for at least $3 \mathrm{~h}$ before measurements of gaseous exchanges began. The sheep were mustered quietly at the end of each $\mathrm{I} h$ measurement period and a sample of blood was immediately withdrawn from a jugular vein. On nineteen occasions a urine sample was also taken either, for ewes, via a catheter that had been kept sealed during the preceding I $\mathrm{h}$, or, for wethers, by placing a hand over the muzzle to restrict breathing and stimulate urination. When the composition of an aliquot sample of exhaled gas had been determined, $\mathrm{CO}_{2}$ was extracted from the remainder of the sample for radioactivity assay.

\section{Expt 4}

Four ewes and three wethers were used; the range in live weight was $3^{1-49} \mathrm{~kg}$. A total of fifty-six measurements of gaseous exchanges was made, each over periods of $90 \mathrm{~min}$, in respiration chambers similar to those used in Expt 2. Methane production was measured and, as proposed by Brouwer $\left(\mathrm{Ig}_{5}\right)$, the term $\left(\mathrm{CH}_{4} \times 0.52\right)$ was included in the calculation of energy expenditure. The temperature within one chamber could be controlled to within $\pm \mathrm{I}^{\circ}$, and, in order to extend the range in energy expenditure, measurements were made at $\mathrm{I}-2^{\circ}$ and at $33-35^{\circ}$ as well as at room temperature $\left(18-22^{\circ}\right)$ on sheep fully fed and fasted for up to $3 \mathrm{~d}$.

Infusions were made through a catheter in an external jugular vein, and were started at least $3 \mathrm{~h}$ before each measurement of gaseous exchanges. A catheter in the other external jugular vein was taken through a gas-tight gland to the outside of the chamber where samples of blood were taken 30,60 and 90 min after the start of each measurement. The SR of the $\mathrm{CO}_{2}$ in each sample was determined, and entry rate over the $90 \mathrm{~min}$ period was calculated from the mean of the three values.

\section{Expt 5}

Three sheep infused intravenously were used to examine the rate of response in $\mathrm{CO}_{2}$ entry rate to change in rate of energy expenditure effected by intermittent exercise on a horizontal treadmill. A wether of $54 \mathrm{~kg}$ live weight walked at speeds varying from $\mathrm{I}$ to $2 \mathrm{~km} / \mathrm{h}$ in several short periods starting $3 \circ \mathrm{min}$ after it was placed on the treadmill. A ewe, $32 \cdot 2 \mathrm{~kg}$, walked continuously for $3 \mathrm{~h}$ at $\mathrm{I} \cdot 5 \mathrm{~km} / \mathrm{h}$; the treadmill was stationary during the preceeding $3 \mathrm{~h}$ and subsequent $4 \mathrm{~h}$. A second wether, $45 \mathrm{~kg}$, walked for $2 \mathrm{~h}$ at $\mathrm{I} \cdot 5 \mathrm{~km} / \mathrm{h}$ after an initial $2 \mathrm{~h}$ at rest; subsequently, after a further $2 \mathrm{~h}$ at rest, it walked for two shorter periods at speeds up to $3 \mathrm{~km} / \mathrm{h}$.

Blood was taken from a jugular vein of each sheep at frequent intervals during the 
periods of rest and exercise, beginning about $8 \mathrm{~h}$ after infusion into the other jugular vein had been started. The $\mathrm{SR}$ of the $\mathrm{CO}_{2}$ in each sample was determined.

\section{RESULTS}

\section{Expt I}

The SR of $\mathrm{CO}_{2}$ in right atrial blood of sheep $\mathrm{B}$ and D (Fig. I) at first increased rapidly, but varied only slightly after the infusions had been in progress for about $3 \mathrm{~h}$. Such a plateau was also observed for the other two sheep throughout the $12-22 \mathrm{~h}$ period of the infusions. Regression analysis of the observations made from 3 or $12 \mathrm{~h}$ to $22 \mathrm{~h}$ showed that there was no significant trend with time in SR while infusion continued; coefficients of variation of mean SR for individual sheep ranged from 6.4 to $1 \mathrm{I} \cdot 7 \%$.

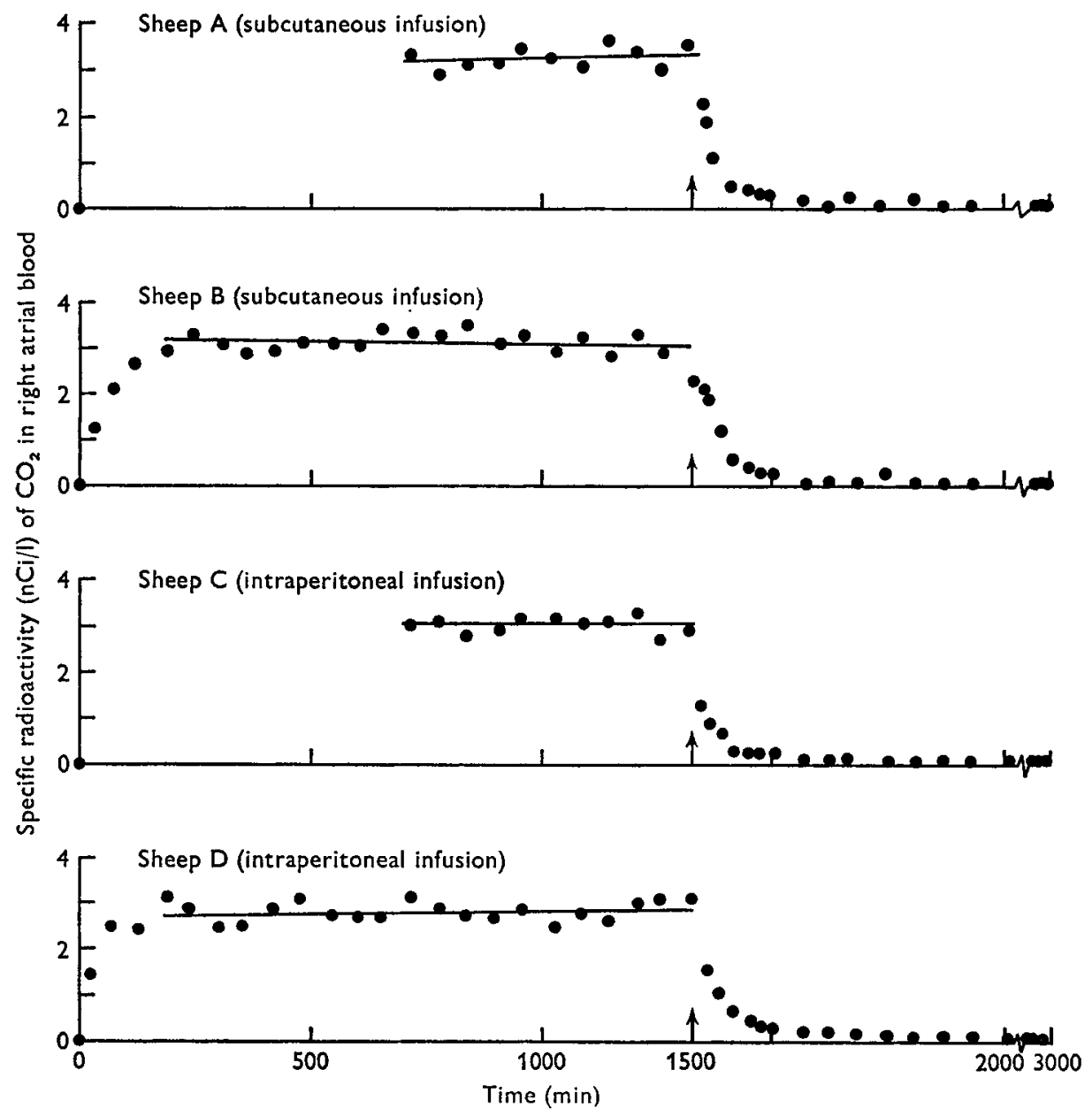

Fig. I. Specific radioactivity of $\mathrm{CO}_{2}$ in right atrial blood of sheep during constant infusion by the routes specified of $\mathrm{NaH}^{14} \mathrm{CO}_{3}$ at the rate of approximately $20 \mathrm{nCi} / \mathrm{min}$, and after cessation of infusion (indicated by arrows). 


\section{Expt 2}

The energy expenditure $(Y)$ of the two ewes varied from 57 to $1 \mathrm{I} 2 \mathrm{kcal} / \mathrm{h}$ and was related rectilinearly to $\mathrm{CO}_{2}$ entry rate $(1 / \mathrm{h})$ estimated from the $\mathrm{SR}$ of $\mathrm{CO}_{2}$ in blood $\left(\mathrm{X}_{b}\right)$ and urine $\left(X_{u}\right)$. The regression equations derived, the standard errors of the regression coefficients (SE), and the residual standard deviations (RSD), based on thirteen and ten observations respectively were:

$$
\begin{array}{lll}
Y=2.63 X_{b}+30.07, & \text { SE } \pm 0.44, & \text { RSD } \pm 8 \cdot 70, \\
Y=4.27 X_{u}-0.12, & \text { SE } \pm 0.75, & \text { RSD } \pm 5.77 .
\end{array}
$$

The RSD were $I I \cdot I$ and $7.9 \%$ of mean $Y$ for equations (I) and (2) respectively. The precision of the equation including both independent variables was not greater than of that including $X_{u}$ alone.

\section{Expt 3}

Regression equations were calculated relating the rate of exhalation of $\mathrm{CO}_{2}\left(Y_{g}, 1 / \mathrm{h}\right)$ to entry rates calculated from radioactivity assay of $\mathrm{CO}_{2}$ in blood $\left(X_{b}^{\prime}\right)$, urine $\left(X_{u}^{\prime}\right)$ and exhaled gas $\left(X_{g}^{\prime}\right)$. Intercepts did not differ significantly from zero, and equations through the origin, based on 42,19 and $4 \mathrm{I}$ observations respectively were:

$$
\begin{array}{lll}
Y_{g}=0.804 X_{b}^{\prime}, & \mathrm{SE} \pm 0.019, & \mathrm{RSD} \pm 2.35 \\
Y_{g}=0.848 X_{u}^{\prime}, & \mathrm{SE} \pm 0.022, & \mathrm{RSD} \pm \mathrm{I} \cdot 84, \\
Y_{g}=0.76 \mathrm{I} X_{g}^{\prime}, & \mathrm{SE} \pm 0.020, & \mathrm{RSD} \pm 2.52 .
\end{array}
$$

The mean rate of respiratory excretion of ${ }^{14} \mathrm{CO}_{2}$ calculated directly was $77.4 \%$ of the rate of infusion as $\mathrm{NaH}^{14} \mathrm{CO}_{3}$. When energy expenditure ( $Y$, range $49-\mathrm{I} 27 \mathrm{kcal} / \mathrm{h}$ ) was taken as the dependent variable the equations obtained were:

$$
\begin{array}{lll}
Y=3 \cdot 44 X_{b}^{\prime}+18 \cdot 12, & \mathrm{SE} \pm 0 \cdot 36, & \mathrm{RSD} \pm 12 \cdot 78 \\
Y=4 \cdot 82 X_{u}^{\prime}-6 \cdot 18, & \mathrm{SE} \pm 0 \cdot 68, & \mathrm{RSD} \pm \mathrm{II} \cdot 02, \\
Y=3 \cdot 20 X_{g}^{\prime}+\mathrm{I} 8 \cdot 78, & \mathrm{SE} \pm 0 \cdot 38, & \mathrm{RSD} \pm 13 \cdot 32 .
\end{array}
$$

The RSD for equations (6), (7) and (8) were respectively $15 \cdot 8,12 \cdot 8$, and $16 \cdot 6 \%$ of mean $Y$. Precision was not increased when any two or all three independent variables were included in multiple regression equations.

There was no significant difference between equations (6) and (I), both based on the radioactivity of blood $\mathrm{CO}_{2}$, nor between (7) and (2) which were both based on the radioactivity of urinary $\mathrm{CO}_{2}$. The equation obtained from all fifty-five observations with blood (Expts 2 and 3$)$ differed $(P<0.05)$ from that obtained from all twenty-nine observations with urine made in the same experiments. These two equations are shown in Fig. 2.

The SR of $\mathrm{CO}_{2}$ in exhaled gas was on average $93.2 \%$ of the SR of blood $\mathrm{CO}_{2}$ determined in Expt 3, but equation (8) did not differ significantly from(6) nor from the equation based on all the blood results. Equation (8) did differ $(P<0.05)$ from that based on all the urine results (Fig. 2). 


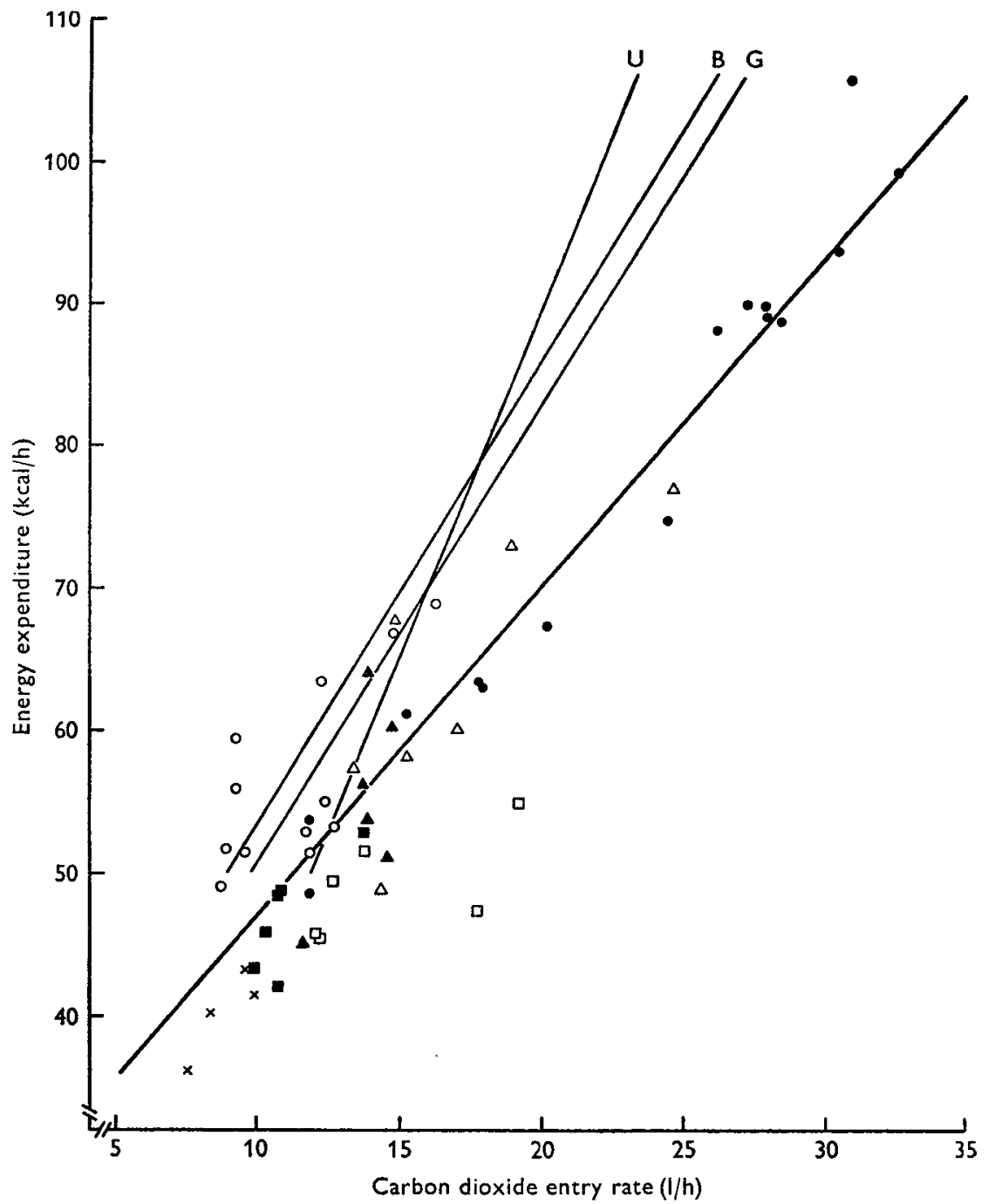

Fig. 2. Relationships between energy expenditure $(Y)$ of sheep estimated from measurements of gaseous exchanges and concurrent estimates of $\mathrm{CO}_{2}$ entry rate made after at least $3 \mathrm{~h}$ of constant infusion of $\mathrm{NaH}^{14} \mathrm{CO}_{3}$. The fifty-six points plotted were obtained from seven sheep infused intravenously in respiration chambers, and entry rates were derived from radioactivity assay of venous blood $\mathrm{CO}_{2}$. The equation for the line (unlabelled) is no. (Io) on p. 285 (Expt 4). Observations for two sheep referred to in the text: $O$, sheep 70I9; 0 , sheep II 3 . The other three lines were obtained from observations, not plotted, on sheep infused subcutaneously. Line $\mathrm{U}$ : twenty-nine observations on penned and grazing sheep combined (from Expts 2 and 3 , see p. 283) where entry rate $(U)$ was derived from radioactivity of urinary $\mathrm{CO}_{2}$. The equation for the line, significantly different from (I0) at $P<0.00 \mathrm{I}$, and $\mathrm{B}$ and $\mathrm{G}(P<0.05)$ is:

$$
Y=4.86 \mathrm{U}-7.7 \mathrm{r}\left(\mathrm{SE}_{b} \pm 0.5 \mathrm{I} ; \mathrm{RSD} \pm 9 \cdot 47\right) \text {. }
$$

Line B: fifty-five observations from penned and grazing sheep combined (Expts 2 and 3 ) where entry rate (B) was derived from radioactivity of venous blood $\mathrm{CO}_{2}$. The equation for the line, significantly different from (10) at $P<0.0 \mathrm{I}$, is:

$$
Y=3 \cdot 24 \mathrm{~B}+2 \mathrm{r} \cdot 07\left(\mathrm{SE}_{b} \pm 0 \cdot 29 ; \mathrm{RSD} \pm 12 \cdot 0 \mathrm{I}\right) \text {. }
$$

Equation for line $\mathrm{G}$, where exhaled $\mathrm{CO}_{2}$ was assayed for radioactivity is no. (8) on p. 283 (Expt 3 ). 


\section{Expt 4}

Significant relationships $(P<0.001,0.01$, and 0.05$)$ were obtained for three sheep with respectively fifteen, twelve and seven observations of energy expenditure ( $Y$, $\mathrm{kcal} / \mathrm{h})$ and entry rate from radioactivity assay of blood $\mathrm{CO}_{2}\left(X_{\mathrm{B}}, 1 / \mathrm{h}\right)$.

The largest number of observations, I 5 , on one sheep (no. I I3 I, Fig. 2) covered the

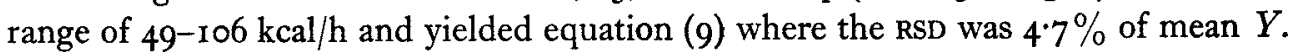
Quadratic or higher terms were not significant.

$$
Y=2.47 X_{\mathrm{B}}+20.56, \quad \mathrm{SE} \pm 0.14, \quad \mathrm{RSD} \pm 3.7 \mathrm{I} .
$$

Regression coefficients did not differ significantly between sheep. There was a difference between intercepts $(P<0.001)$ but this was found to stem from the observations made on one sheep (no. 7019, Fig. 2). When observations from all sheep except no. 7019 were combined the equation obtained had a smaller RSD $(5.07 \mathrm{kcal} / \mathrm{h})$ than, but was otherwise very similar to, equation (10) which is based on all fifty-six observations made over the range of $3^{6-106}$, mean $60 \cdot 1 \mathrm{kcal} / \mathrm{h}$.

$$
Y=2 \cdot 30 X_{\mathrm{B}}+24 \cdot 02, \quad \mathrm{SE} \pm 0 \cdot 12, \quad \mathrm{RSD} \pm 6 \cdot 07 .
$$

This equation from sheep given intravenous infusions, was significantly different from those for sheep given subcutaneous infusions in Expts 2 and 3, whether the comparison was made with the results from analyses of blood $(P<0.01)$, urine $(P<0.001)$ or exhaled gas $(P<0.02)$.

\section{Expt 5}

Changes observed in $\mathrm{CO}_{2}$ entry rates while the sheep were exercised intermittently on the treadmill are shown in Fig. 3. Sheep 2 was unaccountably restless and trembling after the first blood sample was taken and entry rate values increased until it became quiet again after about $2 \mathrm{~h}$.

In general, each increase or decrease in the level of activity imposed on the sheep was reflected ro-20 min later in an increase or decrease in entry rate; maximum responses occurred after from 20 to about $90 \mathrm{~min}$, depending on the duration of exercise.

\section{DISCUSSION}

In Expt $\mathrm{I}$, an apparently constant SR of $\mathrm{CO}_{2}$ was observed after $3 \mathrm{~h}$ of infusion of $\mathrm{NaH}^{14} \mathrm{CO}_{3}$, a result in agreement with those reported by Huber, Mayfield, Huston \& Johnson (1965), Annison, Brown, Leng, Lindsay \& West (I967) and Bergman \& Hogue (1967) for sheep, and White \& Leng (1968) for lambs. This plateau was considered to indicate that the ${ }^{14} \mathrm{CO}_{2}$ had equilibrated with the major compartments in the total body pool of $\mathrm{CO}_{2}$ through which metabolic $\mathrm{CO}_{2}$ passed. It is probable that some equilibration was still continuing in compartments exchanging $\mathrm{CO}_{2}$ slowly, such as that in bone (Buchanan \& Nakao, I952). Bergman \& Hogue (1967) suggested this as a reason for a change of about $3 \%$ in the SR of expired $\mathrm{CO}_{2}$ that they observed during the $3^{\text {rd}}-8$ th hour of infusion, but their sheep were given food ad lib.; these animals 

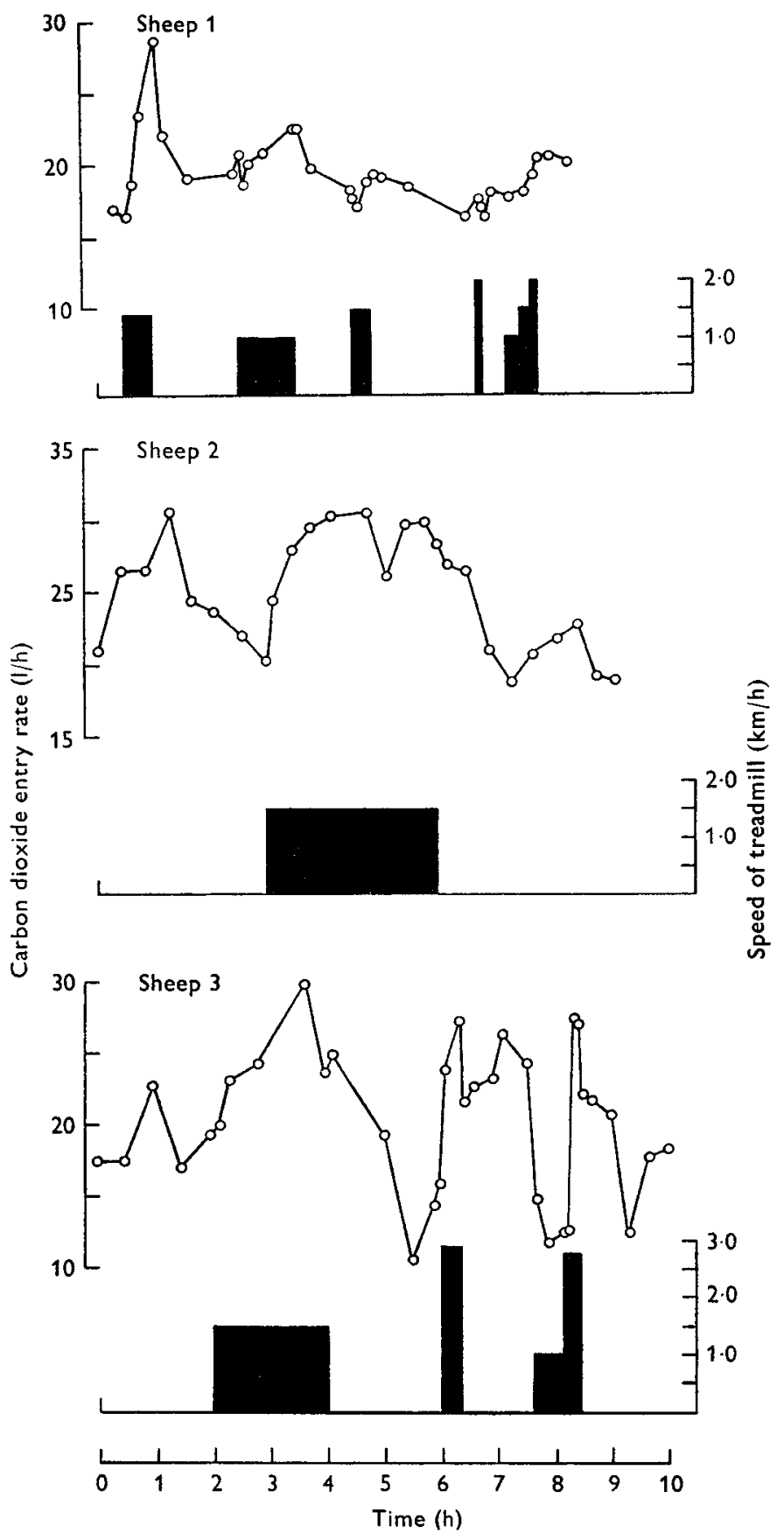

Fig. 3. Changes observed in $\mathrm{CO}_{2}$ entry rate, from radioactivity of venous blood $\mathrm{CO}_{2}$, in sheep infused intravenously while given intermittent exercise on a horizontal treadmill. The duration and speed of periods of walking are indicated by respectively the width and height of the shaded areas. 
probably ate with less regularity than our sheep in Expt $\mathrm{I}$, and $\mathrm{CO}_{2}$ production may have been more variable. The lack of a significant change in SR with time after $3 \mathrm{~h}$ also indicates that recycling of ${ }^{14} \mathrm{C}$ through metabolites subsequently oxidized to produce ${ }^{14} \mathrm{CO}_{2}$ probably had no significant effect.

In subsequent experiments, estimates of $\mathrm{CO}_{2}$ entry rate were made after at least $3 \mathrm{~h}$ of infusion and these were significantly related to energy expenditure for both individual and groups of sheep. However, it might be expected that because of the simple mathematical treatment of the SR values there would be differences between the equations (see Fig. 2), between those where one route of infusion had been used but the site of sampling differed $[(1),(6) v .(2),(7)]$ and those where blood was analysed but route of infusion differed [(I), (6) v. (ro)]. The $\mathrm{CO}_{2}$ produced by tissue metabolism and fermentation of food in, primarily, the rumen, is not distributed in the body as if in a single well-mixed compartment, and there will not necessarily be uniformity in SR throughout the body though a plateau is observed when a particular compartment is sampled.

The SR of $\mathrm{CO}_{2}$ in blood at any particular point in the circulatory system will reflect the $\mathrm{CO}_{2}$ production of the tissues perfused between the sites of infusion and sampling. Though blood is taken from the vena cava close to the heart, or from the right atrium which is often the site for samples referred to as mixed venous blood, it might not include all the $\mathrm{CO}_{2}$ produced by the heart and entering by the coronary circulation. Local differences in SR in the circulatory system may be small and not readily measurable, but blood will not include all $\mathrm{CO}_{2}$ produced in those organs whence it may be removed without entering the general circulation. Among such organs are possibly the lungs and the kidneys, and certainly the rumen. Lungs have active metabolism for a variety of non-respiratory functions (Heinemann \& Fishman, I969), and some $\mathrm{CO}_{2}$ produced may be directly excreted; there is a considerable loss of $\mathrm{CO}_{2}$ in urine (Brouwer, 1958; Graham, 1967); and much of the substantial amount of $\mathrm{CO}_{2}$ produced in the rumen is not absorbed into blood (Hoernicke, Williams, Waldo \& Flatt, 1965) but is eructated.

Eructated $\mathrm{CO}_{2}$, some of which is $\mathrm{CO}_{2}$ from tissue metabolism that has entered by direct transfer across the rumen wall and in saliva, was included in the gas exhaled by the tracheostomized sheep in Expt 3. Even so, the mean recovery of ${ }^{14} \mathrm{CO}_{2}$ from the gas was only $77.4 \%$ of the amount infused, indicating, as do the regression coefficients in equations (3), (4) and (5), that there was a substantial non-respiratory loss of $\mathrm{CO}_{2}$ other than by eructation. The recoveries in similar studies by Bergman \& Hogue (1967) and Annison et al. (1967) were $80 \pm 3$ and $83 \pm 2 \%$ respectively, though in the latter experiment the gas analysed contained no rumen gases unless there were slight leakages to the lungs past the cuffed endotracheal tube then used. There were possibly some losses of $\mathrm{CO}_{2}$ by cutaneous diffusion (Prosser \& Brown, 1961) which would, however, come from the circulatory system and be measured in a respiration chamber, but much of the loss probably occurred by reduction of $\mathrm{CO}_{2}$ to methane. When volumes of methane produced by our fed sheep were measured they were commonly $15-20 \mathrm{l} / \mathrm{d}$, but the SR of the carbon was not determined. There is also removal of $\mathrm{CO}_{2}$ in other metabolites, notably by fixation into urea, and if the animal 
is not in steady state there may be a net loss in, for example, gluconeogenesis from pyruvate and propionate.

The mean SR of the $\mathrm{CO}_{2}$ in exhaled gas was $93.2 \%$ of that in jugular venous blood (Expt 3), probably owing to the presence of rumen $\mathrm{CO}_{2}$, but the equations $(6$ and $\mathrm{I}$ ) and (8) obtained relating entry rate to energy expenditure were similar. These equations were significantly different from the relationship based on the SR of urinary $\mathrm{CO}_{2}$ (Fig. 2). Urinary $\mathrm{CO}_{2}$ would be derived from arterial blood entering the kidneys, while the $\mathrm{CO}_{2}$ in jugular blood would include contributions from the head. The change in route of infusion from subcutaneous (Expts 2 and 3 ) to intravenous (Expt 4 ) was made when it was observed that infusate administered subcutaneously occasionally tended to accumulate near the tip of the catheter. The change altered the course of entry of ${ }^{14} \mathrm{CO}_{2}$ into the multicompartmental body pools of $\mathrm{CO}_{2}$, and was reflected in the significant difference between equation (IO) and those $[(\mathrm{I}),(6)]$ obtained previously from analysis of blood.

Hence an estimate of entry rate, whether derived from a sample of blood, urine or exhaled gas, is not necessarily an absolute measure of the rate of production of $\mathrm{CO}_{2}$ either by the body tissues or the whole animal. It is a practical index of energy expenditure, though the methods of infusion and sampling used in the derivation of a prediction equation and its application must be similar. If $\mathrm{CO}_{2}$ production were to be calculated theoretically from SR values, perhaps with an adjustment for the small amount of air $\mathrm{CO}_{2}$ that entered the body (Buchanan, 1950-1), then it would be necessary to determine the caloric equivalent of the $\mathrm{CO}_{2}$ before the heat production by the animal could be established. In this connexion it is to be determined from further studies on variation between animals in relationships between $\mathrm{CO}_{2}$ entry rate and energy expenditure that these do satisfactorily encompass variation in the respiratory quotient (RQ). It could be expected that at a given energy expenditure, the observed entry rate where RQ was 0.7 would be lower than that determined by the same technique where RQ was $\mathrm{I} \cdot 0$.

In both Expts 2 and 3 the equations were more precise when based upon the SR of urinary, rather than blood, $\mathrm{CO}_{2}$. Possibly this was because samples of blood were taken at intervals of $60 \mathrm{~min}$, whereas the urine sampled had accumulated in the bladder over the period of measurement of gaseous exchanges. Despite probable exchanges of $\mathrm{CO}_{2}$ through the bladder wall, urine may tend to yield an integrated value for SR, encompassing variation in $\mathrm{CO}_{2}$ entry rate during the time it is allowed to accumulate; the $\mathrm{CO}_{2}$ in milk and the carbon of urea might also tend to yield integrated values. In addition, radioactivity assay of the $\mathrm{CO}_{2}$ in urine rather than in blood might be preferred because it will probably be less rapidly affected by transient changes in body $\mathrm{CO}_{2}$ production or output, such as could occur when animals are mustered and restrained to obtain samples.

Collection of blood from sheep has been aided by the development of equipment for continuous automatic sampling (Farrell, Corbett \& Leng, 1970). The $\mathrm{CO}_{2}$ in samples taken continuously over $\mathrm{I2} h$ had SR similar to the mean SR for those periods which were calculated from estimates made every $2 \mathrm{~h}$ and had coefficients of variation of from 7 to $30 \%$. This equipment was not used in Expt 3, but blood samples were 
usually obtained from the sheep within 5 min of first approach in the field, and the results of Expt 5 indicate that the SR values obtained would have been little different from those for the undisturbed state. Indirect evidence that this was so is provided by the similarity of equations (6) and (8) based respectively on radioactivity assays of $\mathrm{CO}_{2}$ in blood taken only at the end of, and exhaled $\mathrm{CO}_{2}$ sampled throughout, the $\mathrm{Ih}$ measurements of gaseous exchanges. The similarity indicates that there may not have been large variation in entry rate during these $\mathrm{I} h$ periods though, because the sheep were at pasture, it might have been as large as would normally be encountered in practice. Young (1968) examined the variation during $24 \mathrm{~h}$ in grazing sheep by obtaining estimates every $2 \mathrm{~h}$ for each of four animals, and used the results to define a practicable scheme for sampling for studying the energy expenditure of similar sheep over many $24 \mathrm{~h}$ periods (Young \& Corbett, 1968, and in preparation). The estimates of entry rate from blood and urinary $\mathrm{CO}_{2}$ for one time differed on average by $2 \mathrm{I}$ and $\mathrm{I} 7 \%$ respectively from those obtained $2 \mathrm{~h}$ before; the smaller change with urinary $\mathrm{CO}_{2}$ is consistent with the precision of equation (2) being greater than (I), and of $(7)$ being greater than (6) and discussed on p. 288.

The equations obtained from observations made in respiration chambers were more precise than those obtained from tracheostomized sheep at pasture. This is to be expected because the calorimetric equipment used indoors was inherently more accurate. A systematic error in the calculation of energy expenditure was introduced by ignoring urinary excretions, and in some experiments the methane production, but the error was probably no more than $\mathrm{r}-2 \%$ (Brouwer, 1958 ). It is unlikely that the increase allowed in $\mathrm{CO}_{2}$ concentration in chamber gas had a significant effect upon the energy expenditure of the sheep or that it would have introduced bias in the relationships with $\mathrm{CO}_{2}$ entry rate. The re-breathing of ${ }^{14} \mathrm{CO}_{2}$ previously excreted would only cause bias where there were large changes with time in the $\mathrm{SR}$ of body $\mathrm{CO}_{2}$ relative to the SR of inspired $\mathrm{CO}_{2}$, which is unlikely during continuous infusion, and if there was significant pulmonary uptake. A sheep was placed in a respiration chamber and ${ }^{14} \mathrm{CO}_{2}$ added to the chamber gas at the rate of about $50 \mathrm{nCi} / \mathrm{min}$; small increases of no practical significance were observed in the $\mathrm{SR}$ of $\mathrm{CO}_{2}$ in venous blood.

Expt 5 was not designed to examine the energy expenditure in horizontal locomotion per $\mathrm{kg}$ live weight, but this may be calculated from the observations made when sheep 2 and 3 walked for 3 and $2 \mathrm{~h}$ respectively at $\mathrm{r} \cdot 5 \mathrm{~km} / \mathrm{h}$. If the baseline for $\mathrm{CO}_{2}$ entry rate for sheep 2 was taken to be $20.541 / \mathrm{h}$, the mean of the first and eighth measurements at $\mathrm{o}$ and $3 \mathrm{~h}$ (see Fig. 3), entry rates increased during exercise and returned to this baseline $76 \mathrm{~min}$ after the $3 \mathrm{~h}$ period of walking ended. The mean increment over the $4 \mathrm{~h} \mathrm{I} 6 \mathrm{~min}$ period was $7 \cdot 3 \mathrm{I} \mathrm{l} / \mathrm{h}$, and on substitution in equation (10), which was derived with other sheep, the total increase in energy expenditure was $69^{\circ} 4 \mathrm{kcal}$, or $0.48 \mathrm{kcal} /$ horizontal $\mathrm{km}$. $\mathrm{kg}$. If the baseline was taken to be the weighted mean of all eight entry rate values determined during the first $3 \mathrm{~h}$, including those made when the sheep was restless and trembling, then the value of $0.2 \mathrm{I} \mathrm{kal} /$ horizontal $\mathrm{km} . \mathrm{kg}$ was obtained. Values obtained in a similar manner for sheep 3 were 0.28 or $0.36 \mathrm{kcal} /$ horizontal $\mathrm{km} . \mathrm{kg}$; the latter was obtained if the third of the five preliminary determinations of entry rate, the highest, was excluded from the calculation of the weighted mean base- 
line. Clapperton (1964) reported energy expenditures for individual sheep, each the mean of four estimates, varying from 0.328 to $0.698 \mathrm{kcal} /$ horizontal $\mathrm{km} . \mathrm{kg}$. The similarity in magnitude of the results obtained in Expt 5 is a demonstration of the serviceability of the $\mathrm{CO}_{2}$ entry rate technique.

The precision of predicted values for energy expenditure may be greater than is indicated by the RSD of the equations because the variability reflects errors in the determination of gaseous exchanges as well as in estimating entry rates. Satisfactory methods have been developed for application of the technique in the field, and it has been used in studies on, particularly, the energy requirement for maintenance of freely grazing sheep in relation to the availability of pasture herbage(Young \& Corbett, 1968, and in preparation). Relationships between $\mathrm{CO}_{2}$ entry rate and energy expenditure have recently been established for cattle (Young, 1970), and where infusion and sampling procedures were similar to those used on sheep the relationships for the two species were not significantly different. The technique may be a useful tool for the examination of many biological problems such as the nutritional efficiency of other domestic livestock both housed and at pasture, wildlife physiology, and energy flow in ecosystems. It seems that it could be developed for use in many species, even including man.

We thank F. Ball, D. J. Brett, M. Inskip, G. S. McArthur and G. H. Parkinson for their skilled technical assistance, and Dr N. McC. Graham for the use of his respiration chambers in Expt 2. Two of us (B.A.Y. and D.J.F.) were in receipt of scholarships from the Australian Wool Board.

\section{REFERENCES}

Annison, E. F., Brown, R. E., Leng, R. A., Lindsay, D. B. \& West, C. E. (1967). Biochem. F. 104, 135. Bergman, E. N. \& Hogue, D. E. (1967). Am. F. Physiol. 213, 1378.

Brockway, J. M. \& McEwan, E. H. (1969). F. Physiol., Lond. 202, 66r.

Brouwer, E. (1958). Publs Eur. Ass. Anim. Prod. no. 8, p. I82.

Brouwer, E. (1965). In Energy Metabolism p. 44I [K. L. Blaxter, editor]. London: Academic Press.

Buchanan, D. L. (1950-I). F. gen. Physiol. 34, 737.

Buchanan, D. L. \& Nakao, A. (1952). F. biol. Chem. 198, 245.

Clapperton, J. L. (1964). Br. F. Nutr. 18, 47.

Corbett, J. L., Leng, R. A. \& Young, B. A. (1969). In Energy Metabolism of Farm Animals p. I77

[K. L. Blaxter, J. Kielanowski \& G. Thorbek, editors]. Newcastle upon Tyne: Oriel Press.

Farrell, D. J., Corbett, J. L. \& Leng, R. A. (I970). Res. vet. Sci. II, 2 I 7.

Flatt, W. P., Waldo, D. R., Sykes, J. E. \& Moore, L. A. (1958). Publs Eur. Ass. Anim. Prod. no. 8, p. Iо .

Graham, N. McC. (1962). Proc. Aust. Soc. Anim. Prod. 4, I 38.

Graham, N. McC. (1967). Aust. F. agric. Res. 18, 467.

Heinemann, H. O. \& Fishman, A. P. (1969). Physiol. Rev. 49, I.

Hoernicke, H., Williams, W. F., Waldo, D. R. \& Flatt, W. P. (1965). In Energy Metabolism p. 165 [K. L. Blaxter, editor]. London: Academic Press.

Huber, T. L., Mayfield, E. D., Huston, R. L. \& Johnson, B. C. (1965). Proc. Soc. exp. Biol. Med. 120, 214.

Leng, R. A., Corbett, J. L. \& Brett, D. J. (1968). Br. F. Nutr. 22, 57.

Leng, R. A. \& Leonard, G. J. (1965). Br. F. Nutr. 19, 469.

Lifson, N., Gordon, G. B. \& McClintock, R. (1955). F. appl. Physiol. 7, 704.

Lifson, N. \& McClintock, R. (1966). \%. theoret. Biol. 12, 46.

Prosser, C. L. \& Brown, F. A. (r962). Comparative Animal Physiology. Philadelphia: W. B. Saunders.

Webster, A. J. F. (1967). Br. F. Nutr. 21, 769.

White, R. G. \& Leng, R. A. (1968). Proc. Aust. Soc. Anim. Prod. 7, 335. 
Vol. 26

Young, B. A. (I968). Maintenance energy requirement of grazing sheep. PhD Thesis, University of New England.

Young, B. A. (1970). Publs Eur. Ass. Anim. Prod. no. 13, p. 237.

Young, B. A. \& Corbett, J. L. (1968). Proc. Aust. Soc. Anim. Prod. 7, 327.

Young, B. A., Leng, R. A., White, R. G., McClymont, G. L. \& Corbett, J. L. (I969). In Energy Metabolism of Farm Animals p. 435 [K. L. Blaxter, J. Kielanowski and G. Thorbek, editors]. Newcastle upon Tyne: Oriel Press.

Young, B. A. \& Webster, M. E. D. (1963). Aust. F. agric. Res. 14, 867. 